\title{
Differentiation of Human and Migratory Water Fowl by Multiplex Escherichia coli Differential Amplification Technique (MECDAT) in South Punjab, Pakistan
}

\author{
Sahar Kiran ${ }^{1}$, Alia Waheed ${ }^{2}$, Aleem Ahmad Khan ${ }^{3}$, Mubashar Aziz ${ }^{4}$, Muhammad Mazhar Ayaz ${ }^{4}$ and Ahsan Sattar Sheikh ${ }^{*}$ \\ ${ }^{1}$ Zoology Division, IPAB, Bahauddin Zakariya University, Multan, Pakistan \\ ${ }^{2}$ Government College for Women, Sahiwal, Pakistan \\ ${ }^{3}$ Department of Zoology, Ghazi University, Dera Ghazi Khan, Pakistan \\ ${ }^{4}$ Department of Pathobiology, FVS, Bahauddin Zakariya University, Multan, Pakistan \\ ${ }^{5}$ Institute of Food, Science and Nutrition, Bahauddin Zakariya University, Multan, Pakistan \\ *Corresponding author: Ahsan Sattar Sheikh, Institute of Food, Science and Nutrition, Bahauddin Zakariya University, Multan 60800, Pakistan, Tel: \\ +92-0322-4058338; E-mail: assheikh@bzu.edu.pk
}

Received date: March 24, 2018; Accepted date: March 26, 2018; Published date: April 02, 2018

Copyright: (c) 2018 Kiran S, et al. This is an open access article distributed under the terms of the Creative Commons Attribution License, which permits unrestricted use, distribution and reproduction in any medium, provided the original author and source are credited.

\begin{abstract}
Escherichia coli, a gram negative, facultative anaerobic, non-sporulating rod, bacteria are commonly found in lower intestine as a part of the normal flora of gut in all warm blooded organisms. Most $E$. coli strains provide many beneficial functions including protection from other pathogenic bacteria. When $E$. coli strains acquire genetic material from others, they can become pathogenic. E. coli strains can be categorized into 5 principal pathogenicity groups; Enteropathogenic E. coli (EPEC), Enteroaggregative E. coli (EAEC), Enteroinvasive E. coli (EIEC), Enterotoxogenic E. coli (ETEC) and Enterohaemorrhagic E. coli (EHEC). All these strains can cause diarrhea, gastrointestinal infections, urinary tract infections, neonatal meningitis and other illnesses in humans as well as in animals. EHEC 0157 is identified readily in the clinical laboratory with standard culturing techniques. All other strain need molecular methods for their presence in any infected materials.
\end{abstract}

In this study we isolated a total of 40 cultures and detected different strains of $E$. coli from humans and birds (water fowls). In all isolates antibiotic sensitivity by disc diffusion method with genetic characterization within the $E$. coli. The result shows that all human E. coli were resistant to 3 antibiotics (Ampicillin, Co-Trimoxazole, and Cefuroxime), while birds $E$. coli strains are sensitive to these antibiotics indicates different genomic lineage. In human isolates EHEC has highest share, however it was not significantly placed. In correlation studies (Pearson's Correlation) indicates that its significance to the use of only chloramphenicol $(p=0.044)$. ANOVA as well as Pearson's and Spearman's coefficients show that there is no association with any of the drugs that could be useful for their treatment. In could be concluded from the antibiotic profile, distribution pattern that the two groups are epidemiologically are different. Furthermore, it appears that birds don't contribute to the spread of disease in humans/animals.

Keywords E. coli; Pathogenicity; Human infection; Antibiotic resistance

\section{Introduction}

Intestinal $E$. coli is well characterized as an opportunistic pathogenic species that causes infection in human and animals [1]. Most of these studies are based on serological identification, virulence factors [2], and the mechanism of pathogenicity [3]. Recently, E. coli 3 strains associated with diarrheal disease is placed into five pathogenicity groups; Enteroinvasive E. coli (EIEC), Enterotoxogenic E. coli (ETEC), Enteroaggregative E. coli (EAEC), Enteropathogenic E. coli (EPEC), and Enterohaemorrhagic E. coli (EHEC). Vero cytotoxinproducing $E$. coli (VTEC)/Shiga toxin-producing E. coli (STEC) are two other common names for later E. coli strains [1,4-7]. Infection with EIEC strains result in watery diarrhea and occasionally dysentery syndrome along with blood, mucus and leukocytes in the stool, tenesmus and fever $[7,8]$. The primary host for these EIEC human infections appears to be similar to the disease caused by Shigella species. [3,9]. Until now they don't have any reported animal reservoirs $[10,11]$. The ETEC outbreaks have been connected to the consumption of contaminated food or water [12]. Strains of ETEC are best known to cause traveler's diarrhea $[12,13]$ and infection to infants in developing countries [3,7]. These subspecies of E. coli don't invade tissues neither they leave the intestine of the host $[14,15]$.

The EAEC on the other hand is most recently been connected to a category of infectious diarrheagenic $E$. coli that adhere to tissue culture cells in vitro. They tend to produce aggregation, adherence and association to produce persistent, watery diarrhea in young children. Till now, no mode of pathogenicity has been elucidated for them in literature [16]. The forth type of $E$. coli (EPEC) induce a profuse watery and bloody diarrhea [17]. It is the leading cause of infantile diarrhea in developing world [3,18]. Transmission has been associated to consumption of contaminated drinking water and meat products, [15]. Molecular pathogenesis of EPEC has proven to involve plasmid mediated protein referred to as EPEC Adherence Factor (EAF) $[17,19]$. 
Citation: Kiran S, Waheed A, Khan AA, Aziz M, Ayaz MM, et al. (2018) Differentiation of Human and Migratory Water Fowl by Multiplex Escherichia coli Differential Amplification Technique (MECDAT) in South Punjab, Pakistan. J Trop Dis 6: 264. doi:10.4172/2329-891X.1000264

Page 2 of 7

The Verotoxin producing E. coli (VTEC) strain infects humans and cause severe complications of Hemolytic Uremic Syndrome (HUS) [20,21]. These are sometime also referred as Enterohaemorrhagic $E$. coli (EHEC) or Shiga toxin-producing E. coli (STEC) [11,22]. All these strains produce Shiga toxin (also known as Verotoxin), a major cause of food borne illness $[23,24]$. The Vero cytotoxin has shown to cause damage to 4 renal and endothelial cells [25].

The best known strains in these organisms have been $0157: H 7$ that have produced devastations in developed countries [26-28]. Most EHEC strains carry a plasmid which encodes a haemolysin gene and chromosomally located Locus of Enterocyte Effacement (LEE) factor $[11,26]$. The avian pathogenic E. coli (APEC) strains also cause intestinal as well as extra intestinal diseases via respiratory tract infection in birds [29-31]. These species share virulence factors that include type 1 and $\mathrm{P}$ fimbriae, coliaerobactin, lipopolysaccharide (LPS), K1 capsular antigen, and Temperature Sensitive Hemagglutinin (TSH) [1]. All of these are linked to uncharacterized specific chromosomal location $[1,32]$.

The APEC strains can cause most common form of colibacillosis that initiates with respiratory infection symptoms (air sacculitis) which later spreads and cause generalized infections (perihepatitis, pericarditis, and septicemia) [33]. Data from some studies show that positive relation exists between APEC and human Extraintestinal Pathogenic E. coli (ExPEC). Numbers of examples are listed in literature like uropathogenic $E$. coli (UPEC) causing uremic syndrome [33-35] and newborn meningitiscausing E. coli (NMEC). This also suggests that some APEC strains could be considered potential zoonotic agents $[1,3,33]$.

In our case, a study was initiated to isolate and genotypically classify E. coli pathogens (groups) from humans and migratory water fowls and find their commonality. This would provide deeper insight about the two reservoirs. Antibiotic patterns within the two groups will also give some evidence about their linkage between human and migratory birds both at genetic as well as phenotypic nature of $E$. coli species.

\section{Materials and Methods}

Pure cultures of $20 \mathrm{E}$. coli human were included in the study after collection from Combined Military Hospital (CMH) Multan Cantonment and other private laboratories of 5 Multan, Pakistan. Further, another 20 were isolated and collected from Water Fowls cloacal/buccal swabs.

\section{Preservation of samples}

The isolated and identified cultures were preserved in MicroBank vials (ProLab, Canada) and kept in freezer at $-80^{\circ} \mathrm{C}$ (Sanyo, Japan).

\section{Study area}

The present study was conducted at Micro/Molecular Biology Laboratory (MMBL), Institute of Pure and Applied Biology (IPAB), Bahauddin Zakariya University Multan.

\section{Media preparation}

All solutions and media were sterilized by autoclaving (Hirayama, Japan) at $121^{\circ} \mathrm{C}$ at $15 \mathrm{lbs} / \mathrm{sq}$. inch for 20 minutes. Each plate (Germany) was made by adding approximately $20 \mathrm{~mL}$ of the selective/ differential media after it cools down to $47^{\circ} \mathrm{C}$. After solidification of the media, they were placed in refrigerator until needed for assay.

\section{Antibiotic sensitivity test}

Each of antibiotic sensitivity tests were performed on Antibiotic Sensitivity Sulfonamide (ASS) Agar (Merck, Germany). All stock culture E. coli were grown overnight in Nutrient broth (Oxide, UK).

Optical density was adjusted to 0.5 OD McFarland's tube and cultures were spread on ASS plate with the help of sterile cultural swabs (China). To each plate an Octadisc ${ }^{\mathrm{Tm}}$ (HiMedia Laboratories, India) with selected antibiotics were placed in the middle of plate with sterilized forceps with gentle press.

The selected Octadiscs $^{\mathrm{ma}}$ were impregnated with antibiotics Tetracycline (TE $30 \mu \mathrm{g}$ ), Gentamicin (GEN $10 \mu \mathrm{g}$ ), Co-Trimoxazole (COT $25 \mu \mathrm{g}$ ), Ceftriaxone (CTR $30 \mu \mathrm{g}$ ), Cefuroxime (CXM $30 \mu \mathrm{g}$ ), Chloramphenicol (C $30 \mu \mathrm{g}$ ), Ampicillin (AMP $10 \mu \mathrm{g}$ ), and Ciprofloxacin $(5 \mu \mathrm{g})$. Plates were incubator overnight. Antibiotic sensitivity was read by millimeter scale next day. The results were recorded as given in Tables 1 and 2.

\section{DNA extraction and PCR}

The DNA was extraction from each isolate with both alkaline lysis method and CTAB methods [36,37]. Multiplex PCR technique was used for detection of different $E$. coli subspecies. The amplifications were done with 8 primers: bfpa, eae, eae-y, lpfa 1.1, lpfa 1.3, lpfa 2.2, stx 1 , stx2. List of primer is provided in Table 1 .

\begin{tabular}{|c|c|c|c|c|c|}
\hline No. & Primers & Primer Sequences $\left(5^{\prime} \AA^{\circledR}\right)$ & Amplicon & Primer (mM in Rx) & $\operatorname{Tm}^{\circ} \mathrm{C}$ \\
\hline \multirow{2}{*}{1} & STX2-F & ATC CTA TTC CCG GGA GTT TAC G & \multirow{2}{*}{587} & 1 & 62 \\
\hline & STX2-R & GCG TCA TCG TAT ACA CAG GAG C & & 1 & 64 \\
\hline \multirow{2}{*}{2} & $E A E-y-F$ & CAG GTT GGG GTA ACG GAC TTT AC & \multirow{2}{*}{472} & 1 & 65 \\
\hline & EAE-y-R & TTG CTT GCG TTT GAG ACT TAC CGT TG & & 1 & 66 \\
\hline \multirow{2}{*}{3} & LPFA1.1-F & GTG CTG GAT TCA CCA CTA TTC ATC GC & \multirow{2}{*}{389} & 0.4 & 68 \\
\hline & LPFA1.1-R & GCC TTG TCT GCA CTG GCA TTA ACT TC & & 0.4 & 68 \\
\hline \multirow{2}{*}{4} & STX1-F & CAG TTA ATG TGG TKG CGA AGG & \multirow{2}{*}{348} & 1 & 60 \\
\hline & STX1-R & CAC CAG ACA ATG TAA CCG CTG & & 1 & 61 \\
\hline
\end{tabular}


Citation: Kiran S, Waheed A, Khan AA, Aziz M, Ayaz MM, et al. (2018) Differentiation of Human and Migratory Water Fowl by Multiplex Escherichia coli Differential Amplification Technique (MECDAT) in South Punjab, Pakistan. J Trop Dis 6: 264. doi:10.4172/2329-891X.1000264

Page 3 of 7

\begin{tabular}{|c|c|c|c|c|c|}
\hline \multirow{2}{*}{5} & BFPA-F & AAT GGT GCT TGG GCT TGC TGC & \multirow{2}{*}{326} & 0.4 & 63 \\
\hline & BFPA-R & GCC GCT TTA TCC AAC CTG GTA & & 0.4 & 61 \\
\hline \multirow{2}{*}{6} & IPFA2.2-F & CTA CAG GCG GCT GAT GGA ACA & \multirow{2}{*}{297} & 0.4 & 63 \\
\hline & IPFA2.2-R & GCT AAT ACC AGC GGC AGC ATC GT & & 0.4 & 66 \\
\hline \multirow{2}{*}{7} & IPFA1.3-F & GGT TGG TGA CAA ATC CCC G & \multirow{2}{*}{244} & 0.4 & 59 \\
\hline & IPFA1.3-R & CGT CTG GCC TTT ACT CAG A & & 0.4 & 57 \\
\hline \multirow{2}{*}{8} & EAE-F & CTT TGA CGG TAG TTC ACT GGA CTT C & \multirow{2}{*}{166} & 0.4 & 66 \\
\hline & EAE-R & GAA GAC GTT ATA GCC CAA CAT ATT TTC AGG & & 0.4 & 68 \\
\hline
\end{tabular}

Table 1: Antibiotic sensitivity result.

All PCR reactions were done on conventional Thermocycler (Eppendorf, Germany) in $20 \mu \mathrm{L}$ reaction volume (Invitrogen, USA). Amplifications were run in two step modules with 55 cycles as indicated in Tables $2 \mathrm{a}$ and $2 \mathrm{~b}$. Amplicons were analyzed on $1 \%$ Agarose (US Biological, USA) in 1X TBE buffer gel electrophoresis in mini gel box (Hoefer, USA) with power supply (Pharmacia, Sweden) at 80 volts. The amplified DNAs were stained in $0.5 \mu \mathrm{g} / \mathrm{mL}$ Ethidium bromide (US Biological, USA) (stock $10 \mathrm{mg} / \mathrm{mL}$ ) for 10 minutes. All DNA bands were visualized under UV light transilluminator (UVtec, USA) and photographed.

\begin{tabular}{|c|c|}
\hline Reaction mixture & Volume requried \\
\hline Template (Sample) & $1 \mu \mathrm{l}$ \\
\hline Master Mix (5X) (REDTaq) & $4 \mu \mathrm{l}$ \\
\hline Primer concentration & $10 \mu \mathrm{l}$ \\
\hline PCR grade water & $5 \mu \mathrm{l}$ \\
\hline Total & $20 \mu \mathrm{l}$ \\
\hline
\end{tabular}

Table 2a: Reaction mixture for PCR.

\begin{tabular}{|c|c|}
\hline Reaction mixture & Volume required \\
\hline Template (Sample) & $2 \mu \mathrm{l}$ \\
\hline Master Mix (5X) (REDTaq) & $4 \mu \mathrm{l}$ \\
\hline Primer conc. & $10 \mu \mathrm{l}$ \\
\hline PCR grade water & $4 \mu \mathrm{l}$ \\
\hline Total & $20 \mu \mathrm{l}$ \\
\hline
\end{tabular}

Table 2b: Reaction mixture for PCR.

\section{Results}

\section{Antibiotic sensitivity}

Comparison of antibiotic sensitivity within the two groups indicates that they belong to two separate clades with some overlapping (Table $3)$.

\begin{tabular}{|c|c|c|c|}
\hline \multicolumn{2}{|r|}{ Groups } & Human Sig. & Birds Sig. \\
\hline \multirow[t]{2}{*}{$\mathrm{TE}$} & Between Groups & \multirow{2}{*}{0.189} & \multirow{2}{*}{0.28} \\
\hline & Within Groups & & \\
\hline \multirow[t]{2}{*}{ GEN } & Between Groups & \multirow{2}{*}{0.353} & \multirow{2}{*}{0.171} \\
\hline & Within Groups & & \\
\hline \multirow[t]{2}{*}{ COT } & Between Groups & \multirow{2}{*}{ - } & \multirow{2}{*}{0.437} \\
\hline & Within Groups & & \\
\hline \multirow[t]{2}{*}{ CTR } & Between Groups & \multirow{2}{*}{0.67} & \multirow{2}{*}{0.904} \\
\hline & Within Groups & & \\
\hline \multirow[t]{2}{*}{ CXM } & Between Groups & \multirow{2}{*}{ - } & \multirow{2}{*}{0.883} \\
\hline & Within Groups & & \\
\hline \multirow[t]{2}{*}{ CIP } & Between Groups & \multirow{2}{*}{0.394} & \multirow{2}{*}{0.189} \\
\hline & Within Groups & & \\
\hline \multirow[t]{2}{*}{ C } & Between Groups & \multirow{2}{*}{0.044} & \multirow{2}{*}{0.855} \\
\hline & Within Groups & & \\
\hline \multirow[t]{2}{*}{ AMP } & Between Groups & \multirow{2}{*}{ - } & \multirow{2}{*}{0.303} \\
\hline & Within Groups & & \\
\hline
\end{tabular}

Table 3: ANOVA ( $\mathrm{N}=40)$ (2 tailed analysis with $E$. coli genetic species).

The human isolates were sensitive to Chloramphenicol ( $\mathrm{p}=0.044$ with CL 95\%) out of 8 antibiotics tested (Table 1). While on the contrary, in bird E. coli isolates does not show any significant association any of the drugs tested (Table 2).

Correlation data indicates that all genetic isolates are negatively related to resistance to antibiotic gentamycin with no significance. In birds, Chloramphenicol is highly negative significant to Cefuroxime. However, Tetracycline, Ceftriaxone show significant association with the type of isolates (Table 4).

Interestingly gentamycin is only drug which is in negative nonsignificant to all isolates. This allows us to infer that resistance in human isolates to 2 nd and 3rd generation antibiotics and in linkage to waterfowls. 
Citation: Kiran S, Waheed A, Khan AA, Aziz M, Ayaz MM, et al. (2018) Differentiation of Human and Migratory Water Fowl by Multiplex Escherichia coli Differential Amplification Technique (MECDAT) in South Punjab, Pakistan. J Trop Dis 6: 264. doi:10.4172/2329-891X.1000264

Page 4 of 7

\begin{tabular}{|c|c|c|c|}
\hline Sr. No. & E. coli Strain & Humans (\%) & Birds (\%) \\
\hline 1 & Atypical EPEC & $3(15.0)$ & $3(15.0)$ \\
\hline 2 & Typical EPEC & $4(20.0)$ & $6(30.0)$ \\
\hline 3 & EHEC & $6(30.0)$ & $4(20.0)$ \\
\hline 4 & STEC & $3(15.0)$ & $2(10.0)$ \\
\hline 5 & LEE-STEC & $1(5.0)$ & 0 \\
\hline 6 & Others & 0 & $1(5.0)$ \\
\hline 7 & Negative & $3(15.0)$ & $4(20.0)$ \\
\hline
\end{tabular}

Table 4: Distribution of different isolates according to genetic E. coli groups.

\section{Multiplex $E$. coli differential amplification technique (MECDAT)}

In this study, the isolated organisms are genetically grouped and resistances to antibiotics are used to address the issue of spread of human strains in birds or vice versa. Results show that Application of Multiplex E. coli Differential Amplification Technique (MECDAT) is successfully applied in surveillance of E. coli in humans / birds. Data on the group's antibiotic sensitograms indicates that the two groups are

with some genetically overlapping differences. Genetic groups show that atypical and typical EPEC share 35\% of human total isolates. While in birds they have about $45 \%$ strains positive. On the other hand, $50 \%$ of human isolates produce shiga toxin as against $30 \%$ in water migratory bird isolates (Table 2).

\section{Discussion}

We isolated total of $40 \mathrm{E}$. coli cultures from humans and migratory birds during migratory bird season. Of these, collected cultures 20 each from human and other 20 from water fowls were included in the study. The human isolates show resistance to 3 antibiotics Ampicillin (AMP), Co-Trimoxazole, and Ceftriaxone (CXM) (Table 1). Each resistance pattern evolves itself through genetic selection/genetic transfer mechanisms $[38,39]$. In literature, it was observed that diarrheal E. coli isolates were $86.4 \%$ resistant to AMP, and $29.6 \%$ to CXM, [40]. On the contrary, in birds E. coli was sensitive to all these antibiotics (Table 1). In Jamaica, study highlights the prevalence of multiple drug resistant $E$. coli among healthy broiler chickens in Jamaica, West Indies, possibly associated with expression of tetracycline resistance [41]. The data show that it didn't appear to be a common source in multiple drug resistance strains of avian or human origin, the genes encoding resistance are similar [41,42]. These results suggest that genes are disseminated in the environment and more investigative certification of the possibility for avian sources acting as reservoirs for tetracycline resistance [41] (Table 5).

\begin{tabular}{|c|c|c|c|c|c|c|c|c|c|c|c|}
\hline \multicolumn{12}{|c|}{ Correlations } \\
\hline \multicolumn{2}{|c|}{ Pearson's Correlation } & \multirow{2}{*}{$\begin{array}{c}\text { Genetic species } \\
1\end{array}$} & \multirow[t]{2}{*}{ Type } & \multirow[t]{2}{*}{ TE } & \multirow[t]{2}{*}{ GEN } & \multirow[t]{2}{*}{ Сот } & \multirow[t]{2}{*}{ CTR } & \multirow[t]{2}{*}{ CXM } & \multirow[t]{2}{*}{ CIP } & \multirow[t]{2}{*}{ C } & \multirow[t]{2}{*}{ AMP } \\
\hline & P. Correlation & & & & & & & & & & \\
\hline & Sig. (2-tailed) & & & & & & & & & & \\
\hline \multirow{2}{*}{ Type } & P. Correlation & 0.013 & 1 & & & & & & & & \\
\hline & Sig. (2-tailed) & 0.938 & & & & & & & & & \\
\hline \multirow{2}{*}{ Tetracycline } & P. Correlation & -0.086 & $0.799^{*}$ & 1 & & & & & & & \\
\hline & Sig. (2-tailed) & 0.598 & 0 & & & & & & & & \\
\hline \multirow{2}{*}{ Gentamycin } & P. Correlation & -0.076 & -0.162 & -0.051 & 1 & & & & & & \\
\hline & Sig. (2-tailed) & 0.639 & 0.319 & 0.755 & & & & & & & \\
\hline \multirow{2}{*}{ Co-Trimoxazole } & P. Correlation & -0.056 & $0.839^{*}$ & $0.632^{*}$ & -0.112 & 1 & & & & & \\
\hline & Sig. (2-tailed) & 0.733 & 0 & 0 & 0.493 & & & & & & \\
\hline \multirow{2}{*}{ Ceftriaxone } & P. Correlation & -0.084 & $0.813^{*}$ & $0.712^{*}$ & -0.05 & $0.796^{*}$ & 1 & & & & \\
\hline & Sig. (2-tailed) & 0.607 & 0 & 0 & 0.759 & 0 & & & & & \\
\hline \multirow{2}{*}{ Cefuroxime } & P. Correlation & 0.139 & $0.673^{*}$ & $0.572^{*}$ & -0.016 & $0.653^{\star}$ & $0.547^{*}$ & 1 & & & \\
\hline & Sig. (2-tailed) & 0.392 & 0 & 0 & 0.921 & 0 & 0 & & & & \\
\hline \multirow{2}{*}{ Ciprofloxacin } & P. Correlation & 0.105 & $0.712^{*}$ & $0.416^{*}$ & -0.256 & $0.682^{*}$ & $0.523^{*}$ & $0.384^{* * *}$ & 1 & & \\
\hline & Sig. (2-tailed) & 0.518 & 0 & 0.008 & 0.111 & 0 & 0.001 & 0.014 & & & \\
\hline \multirow{2}{*}{ Chloramphenicol } & P. Correlation & 0.148 & $-0.343^{* \star \star *}$ & $-0.380^{\star \star * *}$ & -0.009 & -0.271 & $-0.319^{\star \star \star \star}$ & $-0.436^{\star *}$ & 0.102 & 1 & \\
\hline & Sig. (2-tailed) & 0.363 & 0.03 & 0.016 & 0.955 & 0.091 & 0.045 & 0.005 & 0.532 & & \\
\hline
\end{tabular}


Page 5 of 7

\begin{tabular}{|c|c|c|c|c|c|c|c|c|c|c|c|}
\hline \multirow{2}{*}{ Ampicillin } & P. Correlation & 0.006 & $0.874^{*}$ & $0.673^{*}$ & -0.179 & $0.761^{*}$ & $0.770^{*}$ & $0.559^{*}$ & $0.649^{*}$ & -0.278 & 1 \\
\hline & Sig. (2-tailed) & 0.97 & 0 & 0 & 0.268 & 0 & 0 & 0 & 0 & 0.082 & \\
\hline
\end{tabular}

Table 5: Correlation of different factors and Antibiotics with E. coli genetic strains.

In our hand, 17 human samples provide amplifications with 3 with no results (Table 2). EHEC was found to be higher in these isolates with no significance to variants. In birds, a similar pattern, 16 samples showed amplification with 4 being negative (Table 4). Studies by Sjolund and coworkers on wild birds and humans concluded that $E$. coli isolates were similar [42]. Use of Multiplex E. coli Differential Amplification Technique (MECDAT), as used in this study, will provide a long way to identify subspecies with some modifications. Similar results have been cited elsewhere in the literature. ANOVA results as well as correlation coefficients indicate that there is no association with any of the antibiotic that could be useful for their treatment. The Pearson's correlation coefficient on antibiotics showed that Chloramphenicol is significantly placed $(\mathrm{p}=0.044)$ at 0.05 confidence limit. Interestingly in birds, genetic grouping showed overlapping differences to humans. In bird E. coli a typical EPEC class dominates. The EHEC microbe has rarely been reported in wildlife with exception to deer and sporadically in domestic animals and birds $[11,17]$. The presence of EHEC, though in small numbers is important in spread of strain to the farthest flinched area with ease. This also indicates some sort of special association of these E. coli in the digestive tract of human versus birds. In literature special type of pili has been assigned to these E. coli for its colonization [43]. This also has been illustrated from the studies on the gut microbiota of different migratory birds. These findings are unique, and reported first time in these migratory waterfowls from Pakistan. The presence of STEC in humans and birds show minor differences $(15.0 \%$ vs. $10.0 \%)$ respectively (Table 4). Importance of E. coli O157 type infection is partly concludes from this study. But like in other studies, presence of $10 \%$ of STEC appears too much higher than recent investigators identification by Neher et al. from India [44]. Though it is also suggested that presence of seed $E$. coli strain in these waterfowls may be important in the spread of new infections, probably not EHEC, centers from where they can enhance colonization and 9 thereby spread in the community. Such spread has been documented elsewhere in the literature $[45,46]$. In one report, microbiological culturing along with genomics has indicated that an outbreak could occur by indirect contact with wild birds' faeces of VTEC infection in humans [27]. In a two-year study (2007-2009) in Canada, an important conclusion was gathered which confirms the isolation of E. coli $\mathrm{O} 157$ from faecal pats. Presence of these organisms suggest that it is inducted in by contact chain between calves and cattle by ventilation, manure systems and importantly linked to bird number per milking cow [47]. Wildlife is normally not exposed to clinically use of antimicrobial agents, but can acquire antimicrobial resistance through contact with humans, domesticated animals, environment or water polluted with feces new putative infection cycles between wildlife, domesticated animals and humans [48]. Literature has been accumulated which spans for number of years, indicates that strains initially show small antimicrobial resistance to Ampicillin, Gentamicin, Streptomycin, Ciprofloxacin, Chloramphenicol and Tetracycline that later increased to high levels [49]. In a recent study carried out on $101 \mathrm{E}$. coli from broilers and layer hens in Bangladesh with colibacillosis illustrates this similar phenomenon [50]. Another misnomer about avian E. coli isolates is there no pathogenicity. The data on avian pathogenic $E$. coli (APEC) is not yet clear on the significance of infective ExPECs [50-52]. Recent epidemiological studies have shown similitude in isolates of human and avian Extraintestinal Pathogenic Escherichia coli (ExPEC) for their virulence genes [43]. This suggests a probable common pathogenic mechanism in poultry and mankind. Molecular typing on animal faecal and from food samples revealed that they cluster into the same molecular type [51,53]. This also pinpoints that animal/bird faeces might play a significant reservoir role for EHEC 0157 spread. The survival studies in bird's intestinal tract of pathogenic bacteria show that they can survive and can be transferred to humans from food, animals through faecal contact [54]. Data clearly suggest that migratory birds can carry $E$. coli $O 157: H 7$ and 10 disseminates to a large area and distances in short time [54,55]. This all suggests strict monitoring of all possible food contamination to be reinforced $[53,56,57]$. In our data, this plausible issue couldn't be explained, elaborative nor suggested otherwise. However, numerous similar studies provide evidence that APEC ST95 O1 strains cluster with human ExPEC strains. This again clearly demonstrates its zoonotic potential $[58,59]$ which we did not explore further in our work. Study on the APEC strains in a rat model, reveals that APEC's ability to cause meningitis in mammals, including humans their possible potential [60]. This imparts good support to our hypothesis that APEC strains have the potential of zoonosis [30]. Chandran et al. [61], on the contrary, provides evidence to our conclusion that STEC and EPEC isolates were genetically distinct from nonpathogenic $E$. coli and clustered independently. Some researchers conclude that the presence of virulence genes alone cannot be used to determine the pathogenicity of strains. Results show that potentially pathogenic STEC and EPEC strains can be found in some of the avian hosts studied and may contaminate surface water and potentially impact human health [62]. Our study concludes and depicts that strict, continuous monitoring with molecular tools must be a part in epidemiologically important pathogens for predictive suggestions. These notable differences in either human or animals should be made public for better preventive measure as proposed by Ewers and coworkers and others later $[45,63]$. We at this stage also recommend the following:

- Continuous monitoring of 8 commonly used antibiotic resistances in human and from other animals, birds be done.

- More funds for surveillance schemes are allocated globally, especially, in the developing world.

- Pulse Field Gel Electrophoresis (PFGE) profiles and Sequence analysis facilities/centers will enable us to get close to the phylogenic evolution of each strain that is seen in our daily life.

- Contribution of genetic transfer/modifications by extrachromosomal elements is assessed with genetic exchange methods.

- Yearly monitoring in these migratory birds should be done with molecular techniques. 


\section{Conclusion}

In our study, however, waterfowl birds, reported first time, do show less similar patterns within the two groups. Moreover, besides these similarities, differences in the isolates provide some evidence for the lineage that may have common origin as well as addition of any isolated source (Table 4). Recent data on ExPEC microbes show that they produce "newer $\beta$-Lactamases" that are encoded on plasmids that are classified as class C Cephalos porinases (Amp C) $\beta$-Lactamases, Extended Spectrum $\beta$-Lactamases (ESBLs) and Carbapenemases (e.g., Imipenem, Verona Integrons-encoded Metallo- $\beta$-Lactamase (VIM), New Delhi Metallo- $\beta$-Lactamase (NDM types), that are now reported widespread $[1,48]$. Presence of resistance in human isolates, especially with these $\beta$-Lactamases, needs further investigation. Recently Escherichia Albertii is identified as a newly emerging enteric pathogen $[64,65]$ that has been identified in both animals and humans with subclinical association to some birds [66]. Ooka et al. [65] has rightfully identified $E$. Albertii identified different eae gene that might be misidentified as EHEC or EPEC. In our work also some of the isolates, both in human and birds, were not identified by this subspecies identification system and need further improvements that should also include E. Albertii like organisms. Additionally, we showed that a great number of avian ExPEC are probable-Lactamase producing strains, sinceresistance to amoxicillin/clavulanic acid were recorded as $70.4 \%$ in the isolates [50]. Identification of Enterohaemorrhagic strains in birds as well in human quae us to make strict surveillance a mandatory option in food borne pathogens. Thus in future, our focus and concentration would 12 be towards the phylogenic mechanistic evolution in birds and animals using molecular techniques.

\section{References}

1. Mellata M (2013) Human and Avian Extra Intestinal Pathogenic Escherichia coli: infections, zoonotic risks, and antibiotic resistance trends. Foodborne Path Dis 10.

2. Todar K (2007) Pathogenic E. coli. Online textbook of bacteriology. University of Wisconsin-Madison, Wisconsin.

3. Wasteson Y (2001) Zoonotic Escherichia coli. Acta Veterinaria Scandinavica 95: 79-84.

4. Farfan MJ, Torres AG (2012) Molecular mechanisms that mediate colonization of Shiga toxin-producing Escherichia coli strains. Infect Immun 80: 903-913.

5. Qadri F, Svennerholm AM, Faruque A, Sack RB (2005) Enterotoxigenic Escherichia coli in developing countries: epidemiology, microbiology, clinical features, treatment, and prevention. Clin Microbiol Rev 18: 465-483.

6. Beutin L, Krause G, Zimmermann S, Kaulfuss S, Gleier K (2004) Characterization of Shiga toxin-producing Escherichia coli strains isolated from human patients in Germany over a 3-year period. J Clin Microbiol 42: 1099-1108.

7. Nataro JP, Kaper JB (1998) Diarrheagenic Escherichia coli. Clin Microbiol Rev 11: 142-201.

8. Resta-Lenert S, Barrett K (2003) Live probiotics protect intestinal epithelial cells from the effects of infection with enteroinvasive Escherichia coli (EIEC). Gut 52: 988-997.

9. Altenhoefer A, Oswald S, Sonnenborn U, Enders C, Schulze J, et al. (2004) The probiotic Escherichia coli strain Nissle 1917 interferes with invasion of human intestinal epithelial cells by different enteroinvasive bacterial pathogens. FEMS Immunol Med Microbiol 40: 223-229.

10. Valentin L, Sharp H, Hille K, Seibt U, Fischer J, et al. (2014) Subgrouping of ESBL-producing Escherichia coli from animal and human sources: An approach to quantify the distribution of ESBL types between different reservoirs. Intl J Med Microbiol 304: 805-816.

11. Ferens WA, Hovde CJ (2011) Escherichia coli O157:H7: Animal Reservoir and Sources of Human Infection Foodborne Path Dis 8: 465-487.

12. Gonzales-Siles L, Sjoling A (2016). The different ecological niches of enterotoxogenic Escherichia coli. Environmental Microbiology 18: 741-751.

13. Kaper JB, Nataro JP, Mobley HL (2004) Pathogenic Escherichia coli. Nature Rev (Microbiol) 2: 123-140.

14. Smith YC, Rasmussen SB, Grande KK, Conran RM, O'Brien AD (2008) Hemolysin of uropathogenic Escherichia coli evokes extensive shedding of the uroepithelium and hemorrhage in bladder tissue within the first 24 hours after intraurethral inoculation of mice. Infect Immun 76: 2978-2990.

15. Jerse AE, Yu J, Tall BD, Kaper JB (1990) A genetic locus of enteropathogenic Escherichia coli necessary for the production of attaching and effacing lesions on tissue culture cells. PNAS 87: 7839-43.

16. Okhuysen PC, DuPont HL (2010) Enteroaggregative Escherichia coli (EAEC): A Cause of Acute and Persistent Diarrhea of Worldwide Importance. J Infect Dis 202: 503-505.

17. Kenny B, DeVinney R, Stein M, Reinscheid DJ, Frey EA, et al. (1997) Enteropathogenic E. coli (EPEC) transfers its receptor for intimate adherence into mammalian cells. Cell 91: 511-520.

18. Stone KD, Zhang HZ, Carlson LK, Donnenberg MS (1996) A cluster of fourteen genes from enteropathogenic Escherichia coli is sufficient for the biogenesis of a type IV pilus. Mol Microbiol 20: 325-337.

19. Kenny B, Finlay BB (1995) Protein secretion by enteropathogenic Escherichia coli is essential for transducing signals to epithelial cells. PNAS 92: 7991-7995.

20. Dallman TJ, Ashton PM, Byrne L, Perry NT, Petrovska L, et al. (2015) Applying phylogenomics to understand the emergence of Shiga-toxinproducing Escherichia coli O157:H7 strains causing severe human disease in the UK. Microbial Genomics.

21. Bae WK, Lee YK, Cho MS, Ma SK, Kim SW, et al. (2006) A case of hemolytic uremic syndrome caused by Escherichia coli O104: H4. Yonsei Med J 47: 437-439.

22. Karch H, Tarr PI, Bielaszewska M (2005) Enterohaemorrhagic Escherichia coli in human medicine. Intl J Med Microbiol 295: 405-418.

23. Bryan A, Youngster I, McAdam A (2015) Shiga Toxin Producing Escherichia coli. Clin Lab Med 35: 247-272.

24. Tarr PI, Gordon CA, Chandler WL (2005) Shiga-toxin-producing Escherichia coli and haemolytic uraemic syndrome. Lancet 365: 1073-1086.

25. Lynn R, O'Brien S, Taylor CM, Adak BA, Chart H, et al. (2005) Childhood Hemolytic Uremic Syndrome, United Kingdom and Ireland. Emerging Infectious Diseases 11: 590-596.

26. Cabal A, Gomez-Barrero S, Porrero C, Barcena C, Lopez G, et al. (2013) Assessment of Virulence Factors Characteristic of Human Escherichia coli Pathotypes and Antimicrobial Resistance in O157:H7 and NonO157:H7 Isolates from Livestock in Spain. Appl Environ Microbiol 79: 4170-4172.

27. Ejidokun OO, Walsh A, Barnett J, Hope Y, Ellis S, et al. (2006) Human Verocytotoxigenic Escherichia coli (VTEC) O157 infection linked to birds. Epidemiol Infect 134: 421-423.

28. Dallman TJ, Ashton PM, Byrne L, Perry NT, Petrovska L, et al. (2015) Applying phylogenomics to understand the emergence of Shiga-toxinproducing Escherichia coli O157:H7 strains causing severe human disease in the UK. Microbial Genomics.

29. Dou X, Gong J, Han X, Xu Mi, Shen H, et al. (2015) Characterization of avian pathogenic Escherichia coli isolated in eastern China. Gene 576: 244-248.

30. Tivendale KA, Logue CM, Kariyawasam S, Jordan D, Hussein A, et al. (2010) Avian Pathogenic Escherichia coli Strains Are Similar to Neonatal 
Citation: Kiran S, Waheed A, Khan AA, Aziz M, Ayaz MM, et al. (2018) Differentiation of Human and Migratory Water Fowl by Multiplex Escherichia coli Differential Amplification Technique (MECDAT) in South Punjab, Pakistan. J Trop Dis 6: 264. doi:10.4172/2329-891X.1000264

Page 7 of 7

Meningitis E. coli Strains and Are Able To Cause Meningitis in the Rat Model of Human Disease. Infect Immun 78: 3412-3419.

31. Johnson TJ, Kariyawasam S, Wannemuehler Y, Mangiamele P, Johnson SJ, et al. (2007) The Genome Sequence of Avian Pathogenic Escherichia coli Strain O1:K1:H7 Shares Strong Similarities with Human Extraintestinal Pathogenic E. coli Genomes. J Bacteriol 189: 3228-3236.

32. de Pace F, Nakazato G, Pacheco A, de Paiva J, Sperandio V, et al. (2010) The type VI secretion system plays a role in type 1 fimbria expression and pathogenesis of an avian pathogenic Escherichia coli strain. Infect Immun 78: 4990-4998.

33. Solà-Ginés M, Cameron-Veas K, Badiola I, Dolz R, Majó N, et al. (2015) Diversity of Multi-Drug Resistant Avian Pathogenic Escherichia coli (APEC) Causing Outbreaks of Colibacillosis in Broilers during 2012 in Spain. PLoS ONE 10: e0143191.

34. Lloyd AL, Rasko DA, Mobley HL (2007) Defining genomic islands and uropathogen-specific genes in uropathogenic Escherichia coli. J Bacteriol 189: 3532-3546.

35. Anderson GG, Dodson KW, Hooton TM, Hultgren SJ (2004) Intracellular bacterial communities of uropathogenic Escherichia coli in urinary tract pathogenesis. Trends Microbiol 12: 424-430.

36. Stefanova P, Taseva M, Georgieva T, Gotcheva V, Angelov A (2013) A Modified CTAB Method for DNA Extraction from Soybean and Meat Products. Biotech Biotechnol Equip 27: 3803-3810.

37. Willner D, Daly J, Whiley D, Grimwood K, Wainwright CE, et al. (2012) Comparison of DNA Extraction Methods for Microbial Community Profiling with an Application to Pediatric Bronchoalveolar Lavage Samples. PLoS ONE 7: e34605.

38. Blair JMA, Webber MA, Baylay AJ, Ogbolu DO, Piddock LJV (2015) Molecular mechanisms of antibiotic resistance. Nature Rev 13: 42-51.

39. Rodriguez-Rojas A, Rodriguez-Beltran J, Couce A, Blazquez J (2013) Antibiotics and antibiotic resistance: A bitter fight against evolution. Intl J Med Microbiol 303: 293-297.

40. Nguyen TV, Van P, Huy CL, Weintraub A (2004) Diarrhea Caused by Rotavirus in Children Less than 5 Years of Age in Hanoi, Vietnam J Clin Microbiol 42: 5745-5750.

41. Miles TD, McLaughlin W, Brown PD (2006) Antimicrobial resistance of Escherichia coli isolates from broiler chickens and humans. BMC Veterinary Research 2: 7-15.

42. Skurnik D, Olivier C, Andremont A, Picard B, Mekalanos John, et al. (2015) Emergence of Antimicrobial Resistant Escherichia coli of Animal Origin Spreading in Humans. Mol Biol Evol 33: 898-914.

43. Mellata M, Dho-Moulin M, Dozois CM, Curtiss III R, Lehoux B, et al. (2003). Role of avian pathogenic Escherichia coli virulence factors in bacterial interaction with chicken heterophils and macrophages. Infect Immun 71: 494-503.

44. Neher S, Hazarika AK, Barkalita LM, Borah P, Bora DP, et al. (2016) Isolation and characterization of Shiga toxigenic Escherichia coli of animal and bird origin by multiplex polymerase chain reaction. Veterinary World 9: 123-127.

45. Ewers C, Guenther S, Wieler LH, Schierack P (2009) Mallard ducks-a waterfowl species with high risk of distributing Escherichia coli pathogenic for humans. Environ Microbiol Rep 1: 510-517.

46. Hansen DL, Ishii S, Sadowsky MJ, Hicks RE (2009) Escherichia coli populations in Great Lakes waterfowl exhibit spatial stability and temporal shifting. Appl Environm Microbiol 75: 1546-1551.

47. Cernicchiaro N, Pearl DL, McEwen SA, Harpster L, Homan HJ, et al. (2012) Association of wild bird density and farm management factors with the prevalence of E. coli O157 in dairy herds in Ohio (2007-2009) Zoonosis Public Health 59: 320-329.

48. Guenther S, Ewers C, Wieler LH (2011) Extended-spectrum betalactamases producing $E$. coli in wildlife, yet another form of environmental pollution? Front Microbiol 2: 1-13.
49. Giufre M, Graziani C, Marisa A, Luzzi I, Busani L, et al. (2012) Escherichia coli of human and avian origin: Detection of clonal groups associated with fluoroquinolone and multidrug resistance in Italy. J Antimicrob Chemother 67: 860-867.

50. Lima-Filho JV, Martins LV, Nascimento DCO, Venturaa RF, Batistaa JEC, et al. (2013) Zoonotic potential of multidrug-resistant extraintestinal pathogenic Escherichia coli obtained from healthy poultry carcasses in Salvador. Brazilian J Infect Dis 17: 54-61.

51. Maluta RP, Logue CM, Casas MRT, Meng T, Guastalli EAL, et al. (2014). Overlapped Sequence Types (STs) and Serogroups of Avian Pathogenic (APEC) and Human Extra-Intestinal Pathogenic (ExPEC) Escherichia coli Isolated in Brazil. PLoS ONE 9: e105016.

52. Dho-Moulin M, Fairbrother JM (1998) Avian pathogenic Escherichia coli (APEC). Vet Res 30: 299-316.

53. Wang S, Zhang S, Liu Z, Liu P, Shi Z, et al. (2014) Molecular Characterization of Enterohemorrhagic E. coli O157 Isolated from Animal Fecal and Food Samples in Eastern China. Scientific World J 2014: 1-7.

54. Callaway TR, Edrington TS, Nisbet DJ (2014) Isolation of Escherichia coli O157:H7 and Salmonella from migratory brown-headed cowbirds (Molothrus ater), common Grackles (Quiscalus quiscula), and cattle egrets (Bubulcus ibis). Foodborne Pathog Dis 11: 791-794.

55. Botkin DJ, Galli L, Sankarapani V, Soler M, Rivas M, et al. (2010) Development of a multiplex PCR assay for detection of Shiga toxinproducing Escherichia coli, enterohemorrhagic $E$. coli, and enteropathogenic E. coli strains. Front Cell Infect Microbiol 2: 1-10.

56. Wright A, Ginn A, Luo Z (2016) Molecular Tools for Monitoring and Source-Tracking Salmonella in Wildlife and the Environment. Food Safety Risks from Wildlife, pp: 131-150.

57. Besser J (2015) Pulsed-Field Gel Electrophoresis for Disease Monitoring and Control. Pulse Field Gel Electrophoresis 1301: 3-7.

58. Singer RS (2015) Urinary tract infections attributed to diverse ExPEC strains in food animals: Evidence and data gaps Frontiers in Microbiol 6: $1-9$.

59. Dziva F, Hauser H, Connor TR, van Diemen PM, Prescott G, et al. (2013) Sequencing and Functional Annotation of Avian Pathogenic Escherichia coli Serogroup O78 Strains Reveal the Evolution of E. coli Lineages Pathogenic for Poultry via Distinct Mechanisms Epidemiol Infect 134: 421-423.

60. Muller A, Stephan R, Nuesch-Inderbinen M (2016) Distribution of virulence factors in ESBL-producing Escherichia coli isolated from the environment, livestock, food and humans. Sci Total Environ 541: 667-672.

61. Chandran A, Mazumder A (2014) Prevalence of Diarrhea-Associated Virulence Genes and Genetic Diversity in Escherichia coli Isolates from Fecal Material of Various Animal Hosts. Appl Environ Microbiol 79: 7371-7380.

62. Donnenberg MS, Kaper JB (1992) Enteropathogenic Escherichia coli Infect Immun 60: 3953-3961.

63. Pan H, Zhang J, Kuang D, Yang X, Ju W, et al. (2015) Molecular analysis and antimicrobial susceptibility of enterotoxigenic Escherichia coli from diarrheal patients. Diagn Microbiol Infect Dis 81: 126-131.

64. Nimri LF (2013) Escherichia Albertii, a newly emerging enteric pathogen with poorly defined properties. Diagn Microbiol Infect Dis 77: 91-95.

65. Ooka T, Seto K, Kawano K, Kobayashi H, Etoh Y, et al. (2012) Clinical significance of Escherichia Albertii. Emerg Infect Dis 18: 488-492.

66. Oaks JL, Besser TE, Walk ST, Gordon DM, Beckmen KB, et al. (2010) Escherichia Albertii in Wild and Domestic Birds. Emerg Infect Dis 16: 638-646. 